\title{
A Thermogravimetric Study of the Behaviour of Biomass Blends During Combustion
}

\author{
Ivo Jiř́čck ${ }^{1}$, Pavla Rudasová ${ }^{2}$, Tereza Žemlová ${ }^{1}$ \\ ${ }^{1}$ Power Engineering Department, Institute of Chemical Technology, Prague, Technická 5, Prague 6, Czech Republic \\ ${ }^{2}$ Škoda Power, s.r. o., Tylova 1/5\%, 30128 Pilsen, Czech Republic \\ Correspondence to: jiriceki@vscht.cz
}

\begin{abstract}
The ignition and combustion behavior of biomass and biomass blends under typical heating conditions were investigated. Thermogravimetric analyses were performed on stalk and woody biomass, alone and blended with various additive weight ratios. The combustion process was enhanced by adding oxygen to the primary air. This led to shorter devolatilization/pyrolysis and char burnout stages, which both took place at lower temperatures than in air alone. The results of the ignition study of stalk biomass show a decrease in ignition temperature as the particle size decreases. This indicates homogeneous ignition, where the volatiles burn in the gas phase, preventing oxygen from reaching the particle surface. The behavior of biomass fuels in the burning process was analyzed, and the effects of heat production and additive type were investigated. Mixing with additives is a method for modifying biofuel and obtaining a more continuous heat release process. Differential scanning calorimetric-thermogravimetric (DSC-TGA) analysis revealed that when the additive is added to biomass, the volatilization rate is modified, the heat release is affected, and the combustion residue is reduced at the same final combustion temperature.
\end{abstract}

Keywords: straw, lignin, peat, charcoal, combustion behavior, biomass blends, thermogravimetry.

\section{Introduction}

Biomass, such as straw, grasses and wood, is used in various forms for energy production. Many technologies for biomass utilization have been studied in the last two decades, e.g. (co)-combustion, pyrolysis, gasification and liquefaction. These technologies are in various stages of development, whereby combustion is most developed and most frequently applied. Biofuel products are sometimes mixed with other biomass, semi-fossil peat, fossil coal and catalyst to achieve better control of the burning process [1]. Until recently, there have been few studies on the co-firing of biomass blends for energy generation [2]. It is anticipated that blending low-grade biomass with higher-quality biomas will reduce flame stability problems, and will also minimize corrosion effects due to the deposited ash containing low melting point salts. The present work was undertaken to determine whether blending different biomass fuels influences the combustion performance, and whether the addition of a specific char additive can modify the burning velocity in the burnout stage and unify the thermal properties. Non-isothermal thermogravimetry was applied to determine the combustion characteristic of six samples, namely wheat straw, rape straw, flax straw (leftover after scutching), pulp-mill lignin, garden peat, and hardwood charcoal.

\section{Materials and experiments}

All the samples originated from the Eastern EU countries. The initial samples were milled, sieved and seven different particle fractions between $0.08 \mathrm{~mm}<$ $D<2 \mathrm{~mm}$ in diameter were used for the ignition study. For the combustion study, the sample particle size was in the range of $0.15-0.25 \mathrm{~mm}$. This size enables uniform packing on the sample pan. Proximate and ultimate analyses of these biomass samples were made using standard procedures, i.e. the ASTM D 3172-89 method and the TGA method [3]. The gross calorific value (GCV) was determined as per ASTM D2015-66. The results are given in Table 1. Thermogravimetric tests were performed in the TA instruments Q600 simultaneous differential scanning calorimetry-thermogravometry(DSC-TGA) apparatus. The weight precision of the instrument is $0.1 \mu \mathrm{g}$. Small samples weighing about $5 \mathrm{mg}$ were placed in an open platinum sample pan, and uniform packing of the samples was ascertained. The samples were heated to $1000{ }^{\circ} \mathrm{C}$ at a constant heating rate of $10^{\circ} \mathrm{C} / \mathrm{min}$, under a constant air-oxygen flow rate of $120 \mathrm{ml} / \mathrm{min}$ (air flow rate of $100 \mathrm{ml} / \mathrm{min}$ and high purity oxygen flow rate of $20 \mathrm{ml} / \mathrm{min}$ ) through the sample chamber.

The thermograms were analyzed to determine the relevant combustion parameters. $(\mathrm{d} w / \mathrm{d} t)_{\max }$ indi- 
cates the maximum reactivity attained in terms of rate of weight loss $(\% / \mathrm{min})$ at DTG $\left(1^{\text {st }}\right.$ derivative of the TG curve) peak temperatures, $(\mathrm{d} w / \mathrm{d} t)_{\text {mean }}$ is the average rate of weight loss. To determine the ignition temperature, two points on the TG curve were first identified. One is the point at which a vertical line from the sharp DTG peak $(\mathrm{d} w / \mathrm{d} t)_{\max }$ crosses the TG curve. The other is the point at which devolatilization begins. Two tangents drawn to the TG curve at these points intersect at the ignition temperature $\left(T_{i}\right)$. The burnout temperature $\left(T_{B O}\right)$ was obtained in a similar way.

\section{Results and Discussion}

The effect of particle size on ignition temperature was investigated on wheat straw and flax straw samples. Other samples are being tested, and the results will be reported later. The ignition temperature $\left(T_{i}\right)$ for seven particle fractions was found to follow linear behavior between $0.08 \mathrm{~mm}<D<2 \mathrm{~mm}$. Linear regressions gave the following relationships:

$$
\begin{array}{ll}
\text { Wheat straw } & T_{i}\left({ }^{\circ} \mathrm{C}\right)=241.9+2.731 \cdot D, \\
\text { Flax straw } & T_{i}\left({ }^{\circ} \mathrm{C}\right)=265.3+2.427 \cdot D .
\end{array}
$$

These values imply that wheat straw ignites at lower temperatures than flax straw. Although the proximate analysis results differ considerably, the ignition temperatures of the biomass samples changed only in a narrow range, see Table 2.
Generally, volatile matter, flammability of volatiles, and transport from the particle determine whether ignition of an isolated particle occurs heterogeneously or homogeneously (gas ignition). According to thermal explosion theory, heterogeneous ignition characterizes the decrease in ignition temperature as the particle size increases [1]. Our data shows the decrease in ignition temperature as the particle size decreases, which indicates homogeneous ignition. Volatiles seem to evolve early in the combustion sequence. After ignition, they burn in the gas phase, preventing oxygen from reaching the particle surface. When a volatile hydrocarbon is burned, a large number of different oxygen radicals are involved in various radical chain reactions.

The combustion study showed that biomass degradation takes place in two steps: between $180{ }^{\circ} \mathrm{C}$ and $370^{\circ} \mathrm{C}$, volatiles are released and burned (devolatilization/pyrolysis step), and at $370-490{ }^{\circ} \mathrm{C}$ char combustion takes place (oxidation step). Biomass can be divided into three categories according to the heat release process. Most biomass falls into the first category, which is characterized by major heat release in the devolatilization/pyrolysis step. Wheat straw and rape straw are typical representatives of this category, where the predominant form of combustion is gas-phase oxidation of the volatile species, see Figure 1. Peat and pulp-mill lignin fall into the second category, characterized by the highest heat release in the char oxidation step. The third category is reserved for biomass chars.

Table 1: Analyses of the samples in wt. \% dry base and low heat value(LHV)

\begin{tabular}{|l|c|c|c|c|c|c|c|}
\hline Fuel & $\begin{array}{c}\text { Volatile } \\
\text { matter } \\
\text { (wt. \%) }\end{array}$ & Ash & C & K & Cl & S & LHV \\
\hline Wheat straw & 81.0 & 6.6 & 41.6 & 2.36 & 0.11 & 0.10 & 15.5 \\
\hline Rape straw & 79.5 & 3.5 & 40.0 & 2.50 & 0.20 & 0.20 & 14.8 \\
\hline Flax straw & 78.6 & 3.6 & 45.2 & n.a. & 0.06 & 0.04 & 19.1 \\
\hline Pulp-mill lignin & 63.6 & 5.3 & 55.7 & 0.01 & 0.074 & 0.73 & 21.0 \\
\hline Peat & 65.0 & 2.8 & 60.0 & 2.86 & 0.17 & 0.20 & 23.0 \\
\hline Charcoal & 20.8 & 0.6 & 86.0 & 0.43 & 0.001 & 0.01 & 33.0 \\
\hline
\end{tabular}

Table 2: Ignition temperature $T_{i}$, burn-out temperature $T_{B O}$ and combustion characteristic factor $C C F$ for biomass fuels of particle size $0.15-0.25 \mathrm{~mm}$

\begin{tabular}{|l|c|c|c|l|c|c|c|}
\hline Fuel & $T_{i},{ }^{\circ} \mathrm{C}$ & $T_{B O},{ }^{\circ} \mathrm{C}$ & $C C F \cdot 10^{-7}$ & Fuel & $T_{i},{ }^{\circ} \mathrm{C}$ & $T_{B O},{ }^{\circ} \mathrm{C}$ & $C C F \cdot 10^{-7}$ \\
\hline Wheat straw & 243 & 447 & 1.97 & Lignin & 257 & 462 & 1.19 \\
\hline Rape straw & 247 & 448 & 1.98 & Peat & 251 & 445 & 1.40 \\
\hline Flax straw & 266 & 440 & 2.22 & Charcoal & 425 & 513 & 2.95 \\
\hline
\end{tabular}




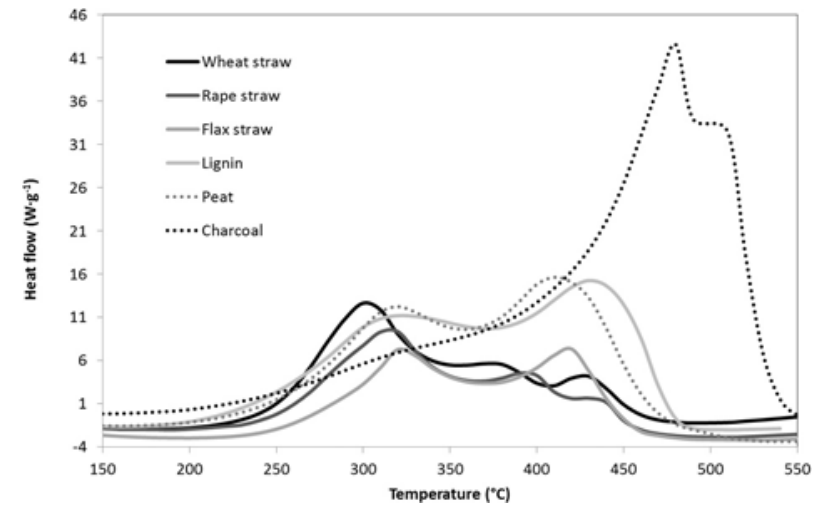

Figure 1: Heat release process in biomass fuels

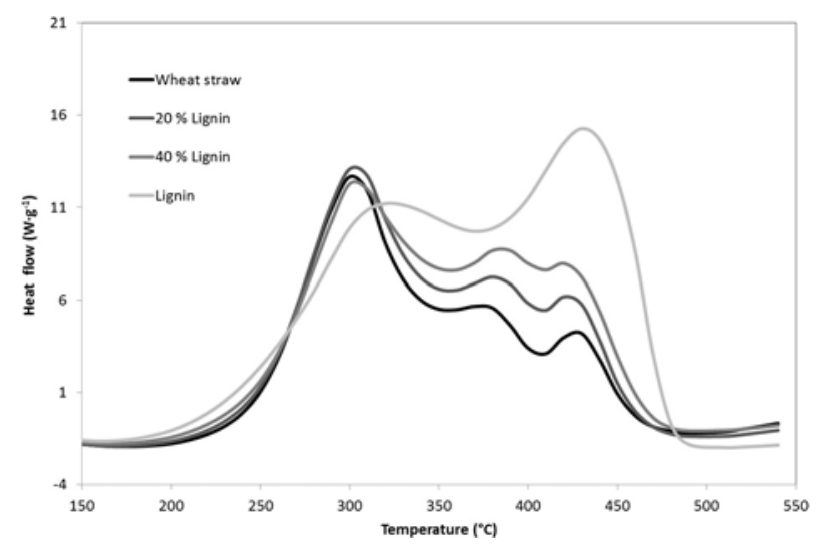

Figure 2: Heat release process in straw-lignin blends

Blending seems advantageous, if samples from different categories are chosen. For example $20 \%$ and $40 \%$ addition of pulp-mill lignin to wheat straw modifies the volatilization rate and affects the oxidation. The heat release is more balanced and more continuous, see Figure 2.

The released heat can be calculated from the DSC curves as:

$$
Q=\beta \int_{\text {ignition }}^{\infty}\left(T-T_{i}\right) \mathrm{d} t=\beta \cdot S=\beta \cdot \Delta w \cdot h,
$$

where $\beta$ is the heat transfer constant from the sample to the metal wall; $S$ is the area under the DSC curve; $\Delta w$ is the average width of the heat release peak; $h$ is the exothermic peak height. Neglecting the difference in the $\beta$ constant between these biomass species, the area under the DSC curve reflects the heat releasing state. However, the value of this heat is lower than the gross calorific value, because of the loss from incompletely burned volatiles.

The effect of the heat release process on charcoal and its blends with the additive is shown in Figure 3. The additive contains a catalyst that enables oxygen transport. The charcoal used in the study seems to have some semi-char content which upon heating degrades up to a temperature of about $500{ }^{\circ} \mathrm{C}$. After this, the final char oxidizing step takes place. If mixed with a suitable ratio of additive, for example below $20 \%$, the heat release can be more continuous, and the burnout temperature decreases; thus, the combustion efficiency is increased. Wood charcoal combustion is a solid phase reaction. A heterogeneous reaction involving carbon is usually slower than a gas-phase reaction, and this seems to be the reason for the higher burnout temperatures $\left(T_{B O}\right)$ that are observed. The difference in burnout temperature between charcoal and other biomass samples was in the range of $51-73^{\circ} \mathrm{C}$, see Tabular 2 . The additive ignites at a temperature of $440^{\circ} \mathrm{C}$ and is burned out at a temperature of $508^{\circ} \mathrm{C}$, which is $5{ }^{\circ} \mathrm{C}$ lower than the burnout temperature of charcoal. The additive blends investigated here were able to lower the burnout temperature of charcoal by up to $4{ }^{\circ} \mathrm{C}$.

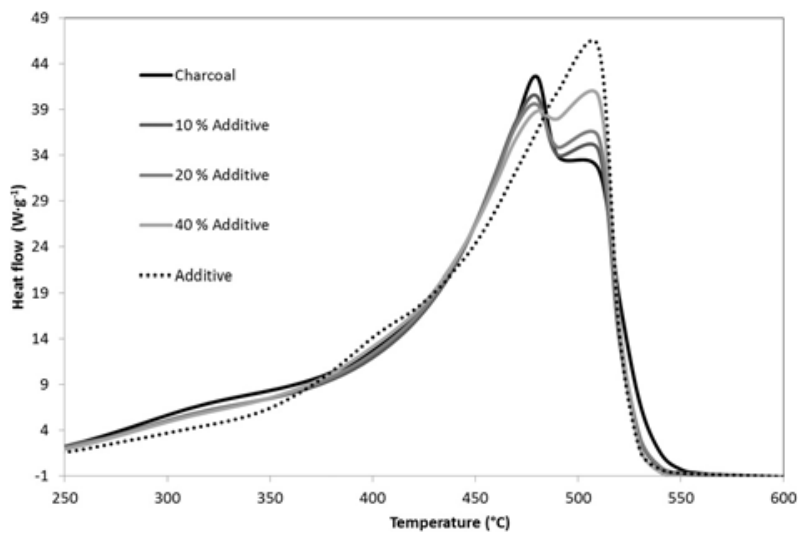

Figure 3: Heat release process in charcoal-additive blends

A parameter called the combustion characteristic factor $C C F$ [4] can be used as a criterion for fuel combustion performance, defined as:

$$
C C F=\frac{\left(\frac{\mathrm{d} w}{\mathrm{~d} t}\right)_{\max } \cdot\left(\frac{\mathrm{d} w}{\mathrm{~d} t}\right)_{\text {mean }}}{T_{i}^{2} \cdot T_{B O}}
$$

where $(\mathrm{d} w / \mathrm{d} t)_{\max }$ and $(\mathrm{d} w / \mathrm{d} t)_{\text {mean }}$ are the maximum and average burning velocity $(\% / \mathrm{min}) ; T_{i}$ and $T_{B O}$ are the ignition temperature and the burnout temperature $(\mathrm{K})$.

This factor, which includes the ease of ignition, the firing velocity and the burnout temperature, is a comprehensive parameter, used here to compare the combustion performance of biomass fuels. $C C F$ values were calculated for several biomass fuels, and are listed in Table 2. With the exception of pulpmill lignin and peat, the values are near to or greater than 2 for all other biomass fuels, indicating their good general burning performance. The $C C F$ values 
for the blends were found to fall between the values of the original fuels. The additive $C C F$ value was found to be the highest. Fuels with the highest $C C F$ values e.g. charcoal $\left(C C F=2.95 \cdot 10^{-7}\right)$ and the additive $\left(C C F=3.23 \cdot 10^{-7}\right)$ suggest that they may be advantageously used for blending with other biomass.

\section{Conclusion}

In this study, thermogravimetric experiments were performed on a number of biomass species intended for use as fuels. Some quantitative characteristics during ignition, devolatilization/pyrolysis, char burning and the burnout stages are listed and compared.

Combustion of wheat straw showed a longer transition stage between volatilization and char burning, so mixing wheat straw with a lignin additive is a method for modifying the biofuel and obtaining a more continuous heat release process.

When an additive is added to charcoal, the heat release is affected and the burnout temperature decreases; thus, the combustion efficiency increases.

The comprehensive parameter $C C F$ for straw biomass fuels and charcoal in this project is near to or greater than 2, indicating good combustion performance.
In further work, we intend to study additives for intensifying heterogeneous charcoal oxidation, which is the slowest step in the overall wood combustion process.

\section{Acknowledgement}

Financial support for specific university research in MSMT project no. 21/2010 is gratefully acknowledged.

\section{References}

[1] Sami, M., Annamalai, K., Wooldridge, M.: Cofiring of coal and biomass fuel blends, Progress in Energy and Combustion Science, 2001, Vol. 27, p. $171-214$.

[2] Van Loo, S., Koppejan, J.: The handbook of biomass combustion and co-firing. Earthscan, 2008, p. 22-38. ISBN 978-1-84407-249-1.

[3] Jiříček, I., Žemlová, T., Macák, J., Janda, V., Viana, M.: Paliva, 2009, Vol. 1, p. 19-22.

[4] Nie, Q. H., Sun, S. Z., Li, Z. Q.: Thermogravimetric analysis of the combustion characteristic of the brown coal blends, Combustion Science and Technology, 2001, Vol. 7, p. 71-76. 